\title{
Experimental Study of Soil Thermal Properties Based on the Transient
}

\section{Method}

\author{
Qi-zhi Hu ${ }^{1, a}$, Jian $\mathrm{Li}^{2, \mathrm{~b}}, \mathrm{Jian} \mathrm{Lin}^{3, \mathrm{c}}$ and Chao Xie ${ }^{4, \mathrm{~d}}$ \\ ${ }^{1}$ Hubei Wuhan, China,430068, ${ }^{2}$ Hubei Wuhan, China,430068, \\ ${ }^{3}$ Hubei Wuhan, China,430068, ${ }^{4}$ Hubei Wuhan, China,430068

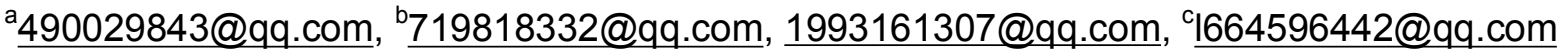 \\ The first author introduction: Qi-zhi Hu, male, 1969.10, Professor, Ph.D., mainly engaged in the geotechnical engineering materials and geothermal \\ development and application of teaching and scientific research work. ,Hubei Wuhan ,China.
}

Key words: GSHP; Thermal Conductivity; Transient Plane Source Method; Moisture content; Dry density Abstract: The soil thermal conductivity is an important parameter of heat efficiency in the application of ground source heat pump. We based on the principles of Transient Plane Source Method and selected clay and sandy soil from Yangtze River in Wuhan, using DRE - III multi-function rapid thermal conductivity tester to carry out soil thermal properties test under the condition of different water content, different dry density and different ratio of sand to clay. The results show that Coefficients of thermal conductivity of sand and clay increase with the increase of water content and dry density, and the effect of the water content is larger than that of dry density. In the thermal properties of sand and clay mixture experiment, it has the highest thermal conductivity when the ratio of sand to clay is $2: 1$. We analyzed the test results on the basis of experiment, and discussed the soil thermal properties and change mechanism. This study provides an important reference for the application of backfill to buried pipe in geothermal applications.

\section{Introduction}

Geothermal energy is a kind of clean and environment-friendly power source from the earth's crust. Under the condition of global warming and energy getting increasingly scarce, the development and utilization of geothermal resources become more and more important. Shallow geothermal resources of ground source heat pump technology is an effective measure to solve the problem of air conditioning system energy and the environment, which has been applied widely in North America and parts of Europe. Ground source heat pump technology, using the energy as heat source in the soil, can save electricity and lessen pollution to the environment, which has become a sustainable development projects in the field of energy utilization ${ }^{[1]}$.In recent years, many researchers began to study on soil thermal physical properties, especially the coefficient of thermal conductivity. The design of Ground source heat pump needs to consider the depth and the number of ground tube embedment, which need to be decided by thermal physical properties of the backfill soil (coefficient of thermal conductivity and thermal diffusivity, etc. ${ }^{[2]}$. Thus, accurate measurement of the soil thermal properties parameters not only have a great significance to the development and utilization of shallow geothermal resources, but also will save project's initial investment.

The study shows that the influence of the change of soil water content on soil thermal conductivity is more obvious. The current study mostly adopts the undisturbed soil, but backfill soil, contacted with buried pipeline, is often used in ground source heat pump. The heat conduction performance is good or will not directly affect the heat transfer efficiency of the heat pump system. 


\section{Experimental design}

Soil is a granular media, which include solid, liquid and gas phase. This article regards the three parameters relationship of proportion as the main influence factors of affecting soil coefficient of thermal conductivity , and establish the relation that the influence of the change of various factors on the coefficient of thermal conductivity. Study shows that the coefficient of thermal conductivity can use the function relation between the water content and dry density ${ }^{[3]}$ :

$$
\lambda=f\left(\rho_{d}, \omega\right)
$$

Where $\lambda$ is the soil coefficient of thermal conductivity $\left(\mathrm{w} \cdot \mathrm{m}^{-1} \cdot \mathrm{k}^{-1}\right), \rho_{\mathrm{d}}$ is the dry density of soil $\left(\mathrm{g} / \mathrm{cm}^{3}\right)$ and $\omega$ is the soil water content (\%).

\subsection{The transient heat source method}

The transient heat source method is a kind of unsteady-state method, widely used in recent years, which can accurately measure the coefficient of thermal conductivity of the soi ${ }^{[4]}$, because the effects on soil water movement are far smaller for these methods than they are for steady-state methods. The transient heat source method has the following advantages:(1)It can save a lot of time to measure the heat transmission;(2) It overcome shortcomings that the steady-state method is influenced by the large area of the contact thermal resistance, only need to measure the temperature of the sample point that can get material coefficient of thermal conductivity, which makes the result more accurate;(3) The soil sample preparation requirements is not high, just make the sample surface flat and level.

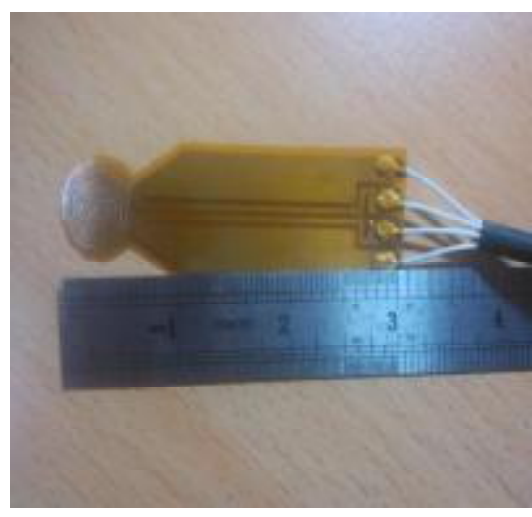

Fig.1Nickel probe schematic

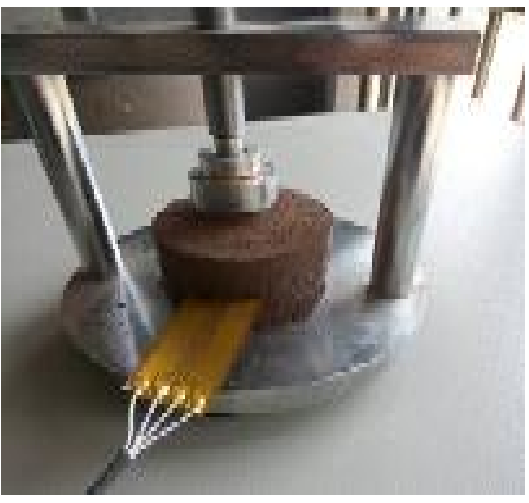

Fig.2 Diagram of the sample probe and sample

This experiment adopts transient plane heat source method, ${ }^{[5]}$ whose basic principle is to use the thermal resistance material (nickel Fig.1) that be made into a plane probe. Because the thermal resistance coefficient of nickel has a linear relationship with temperature and resistance, it can be concluded the loss of the heat through the change of the thermal resistance, which reflects the thermal conductivity of the sample. In the experiment, the probe was placed in the middle of the two samples (Fig.2). The surface of the probe can produce certain temperature rise when current got through it, then probe added hot to sample at a constant power, and generated heat spread around the sample. This instrument can measure three sets of data automatically when the temperature reaches stability $(0.5 \mathrm{~h})$ to record the change of the average temperature of the probe, and get the coefficient of thermal conductivity of soil sample through the mathematical model. The model is as follows:

The probe resistance expressed in the type of change over time: 


$$
R(t)=R_{0}\left[1+\alpha \Delta T_{i}+\alpha \Delta T(\tau)\right]
$$

Where $\mathrm{R}_{0}$ is probe resistance value when $\mathrm{t}=0(\Omega)$, $\alpha$ is temperature coefficient of the probe resistance $(1 / \mathrm{K}), \triangle \mathrm{Ti}$ is the temperature difference of probe film and $\Delta \mathrm{T}(\tau)$ is the average temperature rise of probe. $\Delta \mathrm{T}(\tau)$ can be represented as:

$$
\Delta \mathrm{T}(\tau)=\frac{Q}{\pi^{3 / 2} r \lambda} D(\tau)
$$

Where $\mathrm{Q}$ is power output of $\operatorname{probe}(\mathrm{W}), \mathrm{r}$ is the probe $\operatorname{radius}(\mathrm{m}), D(\tau)$ is the dimensionless time function.

$$
\begin{gathered}
\tau=\sqrt{\frac{t}{\theta}} \\
\theta=\frac{r^{2}}{a}
\end{gathered}
$$

Where $\theta$ is the characteristic time(s), a is the thermal conductivity of the soil sample. We

make $y=R_{0}\left(1+\alpha \Delta T_{i}\right)$ and $\mathbf{k}=\alpha R_{0} \frac{Q}{\pi^{3 / 2} \gamma \AA}$, then combine with formula (3) to obtain

$$
\mathrm{R}(\mathrm{t})=\mathrm{y}+\mathrm{kD}(\tau)
$$

Thermal conductivity and the diffusion rate of calculation is an iterative process. We regard time correction $t$ as optimization variables and establish a liner relationship, then obtain the coefficient of thermal conductivity.

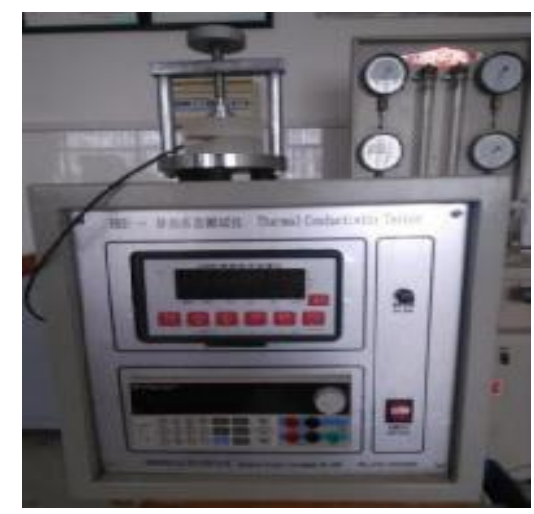

Fig.3 DRE-III multifunction rapid thermal conductivity tester

\subsection{Testing apparatus}

This experiment adopts the equipment, a rapid thermal conductivity tester called DRE - III multi-function(Fig.3), which is produced by Hunan Xiangtan Instrument Corporation in China. The principle of the Instrument is based on transient heat source method, which can directly measure the heat transmission, save a lot of time, measuring speed, have a wide application scope, and can avoid the effect of natural convection in the experimental process. This instrument can measure the coefficient of thermal conductivity of solid, geotechnical, powder, liquid, paste, coating and film. 


\subsection{Test procedure}

\subsubsection{Soil sample preparation}

Sample of material was clay and sandy soil, which was selected from the Yangtze River in Wuhan. Sample preparation accorded to GB/T50123-1999 "standard of soil test method" relevant provision with ring knife method (diameter is $100 \mathrm{~mm} * 30 \mathrm{~mm}$, Fig.2).

First, we put the clay and sand drying and dolly, using vibration sieve machine screen out particles of different size, and obtain the required sandy soil and clayey soil samples (Table 1 and Table 2), and then produce four kinds of soil samples with pure clay, sand, clay and sand mix ratio of 1:2 and 2:1 respectively, making different samples for each type of soil under the different water content and different dry density, placing the sample inside the aquarium stand for $24 \mathrm{~h}$ under the condition of sprinkling water on its surface. In this test, we prepared a total of 84 samples, including 30 pure clay samples, 30 pure sand samples, and 24 samples with different composition of the soil.

Table1 Clayey soil sample

\begin{tabular}{ccccc}
\hline \multirow{2}{*}{ Indicators } & \multicolumn{3}{c}{ Particle size range $/ \mathrm{mm}$} & \multirow{2}{*}{ Subtotal } \\
\cline { 2 - 4 } & $<0.075$ & $0.075-0.250$ & $0.250-0.500$ & \\
\hline Quality percentage /\% & 4.2 & 42.9 & 52.9 & 100 \\
\hline \multicolumn{5}{c}{ Table2 Sandy soil sample } \\
\hline Indicators & \multicolumn{3}{c}{ Particle size range /mm } & \multirow{2}{*}{ Subtotal } \\
\cline { 2 - 4 } & $0.161-0.18$ & $1.18-4.75$ & $>4.75$ & 100 \\
\hline
\end{tabular}

\subsubsection{Sample measurement}

Compared Tests had been conducted in every kind of samples through controlling the change of water content and dry density of soil.(1)We configured a certain moisture content of soil, then maintained moisture content constant and changed the soil dry density, so that the influence of different dry density on soil thermal conductivity can be compared and analyzed.(2) We took a certain amount of dry soil, then kept the dry density of soil the same, and changed the soil water content, so that the influence of different water content on soil thermal conductivity can be obtained and analyzed.(3)We configured two kinds of soil that include sandy soil and clay whose mix proportion is 2:1 and 1:2 respectively, then measured coefficient of thermal conductivity of two kinds of soil with moisture content in $0 \%, 5 \%, 10 \%, 15 \%, 20 \%$, $25 \%$. 


\section{The analysis of test result}

\subsection{The influence of dry density on the coefficient of thermal}

\section{conductivity of sand and clay}

According to the experimental results, we obtained the coefficient of thermal conductivity of sand and clay with the change of dry density when water content is $0 \%, 5 \%, 10 \%, 15 \%$ and $10 \%$ respectively.

As can be seen from Fig. 4 and Fig.5, the coefficients of thermal conductivity in the clay and sand soil increase with the rise of dry density. The growth of sandy soil coefficient of thermal conductivity is $90.3 \%$, the clay is $78.3 \%$ when its soil water content is 0 and dry density increased from $1.2 \mathrm{~g} / \mathrm{cm}^{3}$ to 1.7 $\mathrm{g} / \mathrm{cm}^{3}$. The growth of sandy soil coefficient of thermal conductivity is $20.7 \%$, the clay is $13.6 \%$ when its soil water content is $20 \%$ and dry density increased from $1.2 \mathrm{~g} / \mathrm{cm}^{3}$ to $1.7 \mathrm{~g} / \mathrm{cm}^{3}$.

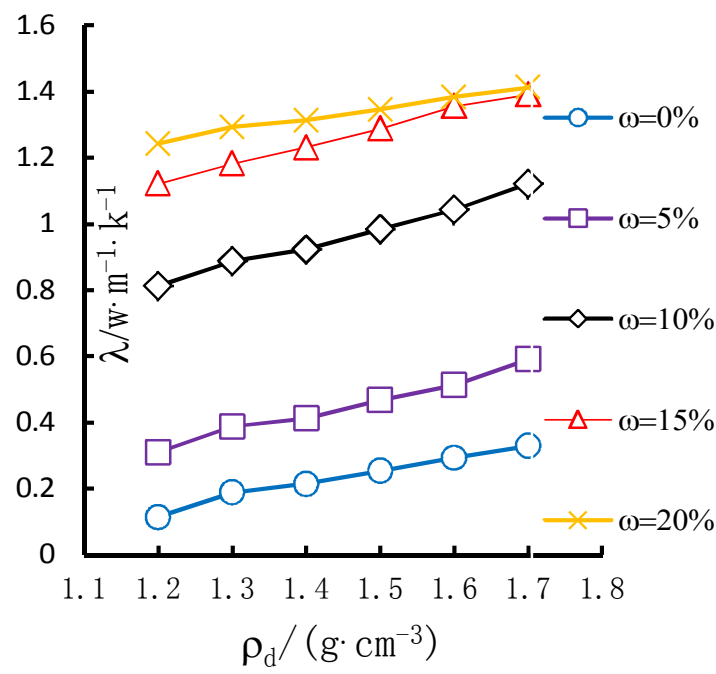

Fig.4 Curve of pure sand density and thermal conductivity

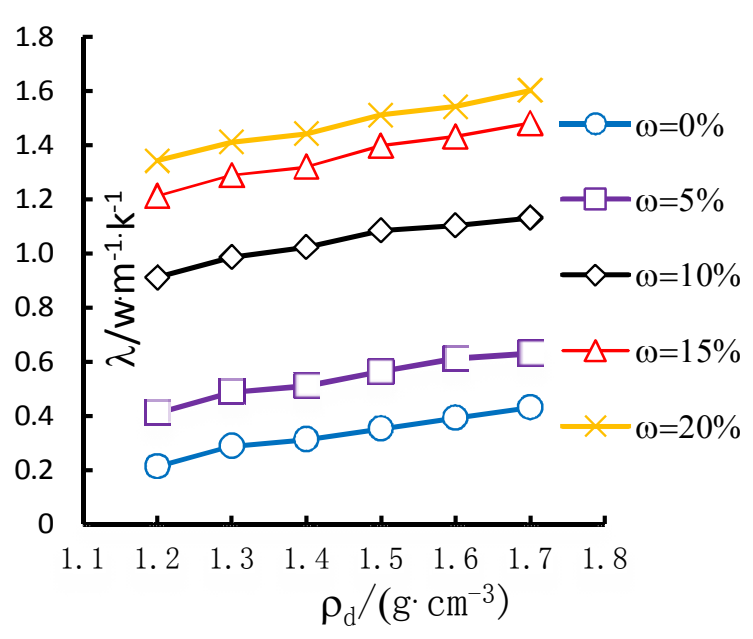

Fig.5 Curve of pure clay dry density and thermal conductivity

Dry density of soil is obtained by the ratio between the quality of dry soil and the total volume of soil, while the coefficient of soil thermal conductivity is decided by three-phase component that include soil particles, water and air., so the change of soil dry density affects the coefficient of soil thermal conductivity. Fever is caused by particles activity, the higher the temperature is, the more intensely the particles act..Heat transfer is achieved by active particles collisions with inactive particles. In the air, the distance between the molecules and molecular is very big, which made its collision probability small ,then its heat transfer become slow, while molecules distance in the liquid and solid state is small, which made its collision probability get higher, so their heat transfer is faster than that of air.

Relevant research pointed out that the coefficient of thermal conductivity of water is about 0.6 $\mathrm{W} /(\mathrm{m} \cdot \mathrm{k})$, while the coefficient of thermal conductivity of air is only $0.0257 \mathrm{~W} /(\mathrm{m} \cdot \mathrm{k})^{[6]}$, so the coefficient of thermal conductivity of the air is much less than that of water and soil. The soil porosity refers to the ratio of soil pore volume to the total volume in its natural state, so the influence of soil porosity on thermal conductivity is not big, but soil porosity decide distribution of three-phase substances in soil when it did not reach saturation in soil samples. We can't make the water distribution uniform under the 
condition of low moisture content through stirring measures, which lead to a conclusion that water will form a liquid bridge between soil particles and cause certain soil particles at a state of groups, then it makes soil loose at this present state, at this point the soil thermal conductivity mainly depends on the soil particle content. From what has been discussed above, we conclude that with the increase of mass fraction of soil particles, the spacing between soil particles decreases, and the air volume become smaller and smaller when water content was $0 \%$, which made the coefficient of thermal conductivity of soil increase with the increase of dry density. From Fig. 6 and Fig. 7 ,the growth trend of soil thermal conductivity slows down with the increase of dry density when the water content increases on the ground that water will be distributed more evenly between the soil particles with the increase of water content. At this time, the water content will have greater effects on soil thermal conductivity.

\subsection{The influence of water content on coefficient of thermal}

\section{conductivity of sand and clay}

Fig. 6 and Fig. 7 display the coefficient of thermal conductivity with the change of moisture content of soil when the soil dry density is $1.6 \mathrm{~g} / \mathrm{cm} 3$. Overall, the coefficient of thermal conductivity of soil can increase with the increase of water content of soil no matter what kind of soil samples. When water content from $0 \%$ to $15 \%$, the coefficient of thermal conductivity of four kinds of soil samples are linear increase, which include the coefficient of thermal conductivity of clay growth is $352.94 \%$, sandy soil coefficient of thermal conductivity growth is $268.69 \%$, the ratiol:2 of clay and sand growth is $262.96 \%$, the ratio $2: 1$ of clay and sand growth is $223.5 \%$. When water content from $15 \%$ to $25 \%$, the coefficient of thermal conductivity growth rate start to slow, which include the coefficient of thermal conductivity of clay growth is $6.02 \%$, sandy soil coefficient of thermal conductivity growth is $5.68 \%$, the ratio1:2 of clay and sand growth is $2.46 \%$, the ratio $2: 1$ of clay and sand growth is $4.25 \%$.

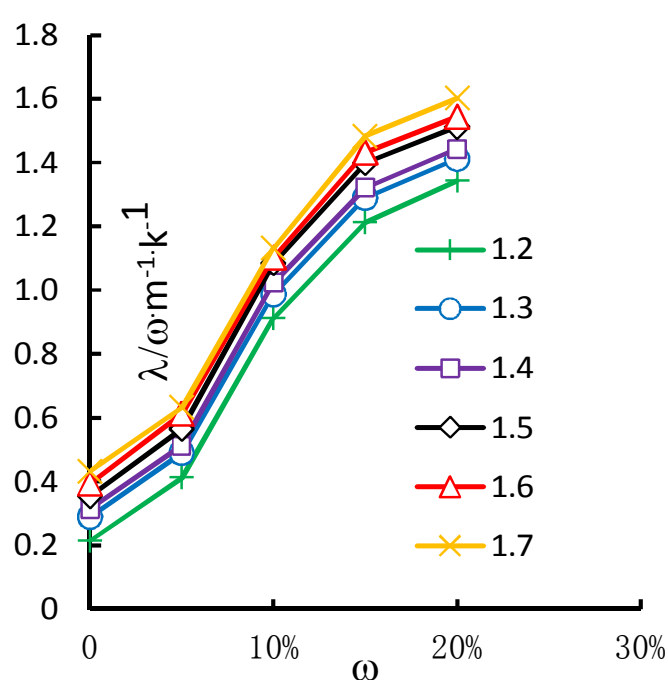

Fig.6 The curve of thermal conductivity in pure sandy soil moisture content

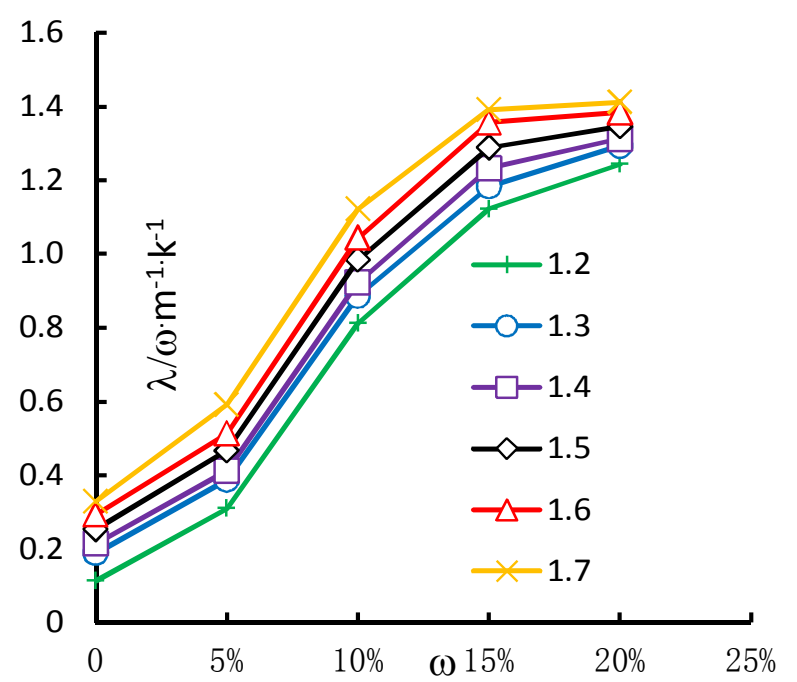

Fig.7 The curve of thermal conductivity in pure clay soil moisture content 
From the analysis, the change of water content in soil influence on the thermal conductivity of soil sample is relatively large. The first reason is that the increase of water content cause gas volume decreases and gradually replaced by water in the three-phase composition of soil when the dry density is constant, and the coefficient of thermal conductivity of air is far less than the coefficient of thermal conductivity of water, so it will lead to increase of thermal conductivity. Another reason is that with the increase of soil water content, it will form liquid bridge between soil particles, which lead to a phenomenon that gravity of soil particle will become large under the condition of the existence of liquid bridge, making the space among soil particles and thermal resistance among soil particles small, so the coefficient of thermal conductivity of soil increases.

The soil thermal conductivity increases relatively slowly when the water content ranges from $0 \%$ to $5 \%$ on the grounds that the state of part of soil is loose under the condition that the early stage of the water mass fraction is low. With the increase of water content, water in the soil will distribute more and more uniformly, and the liquid bridge between soil particles will be mutually interconnected, so the coefficient of thermal conductivity growing trend is steep at this time. The apparent volume of soil will increase slightly when the water content surpasses $15 \%$, which makes most of water construct the water bridge, only a few big pores in soil have no water. If we continue to increase the moisture, it will only fill large pore. To sum up, the coefficient of thermal conductivity increase slowly at this time. But due to the increase of water content, soil coefficient of thermal conductivity is still increasing as a whole. From the above analysis, the effect of the water content on soil thermal conductivity is relatively large.

\subsection{The influence of a mixture of sand and clay on the coefficient of}

\section{thermal conductivity}

The coefficient of thermal conductivity is the highest among all soil samples when a mixture ratio of sand to clay is $2: 1$ from the curve in Fig. 8. This phenomenon shows that the soil composition also can have certain influence on the soil coefficient of thermal conductivity in the backfill soil of buried pipe. If we fill in this soil, which is made of a mixture of sand and clay whose ratio is $2: 1$, around the buried pipe, it may improve the thermal conductivity of the soil ability, enhance heat transfer around the heat exchanger, greatly improve the utilization of geothermal energy and save the cost.

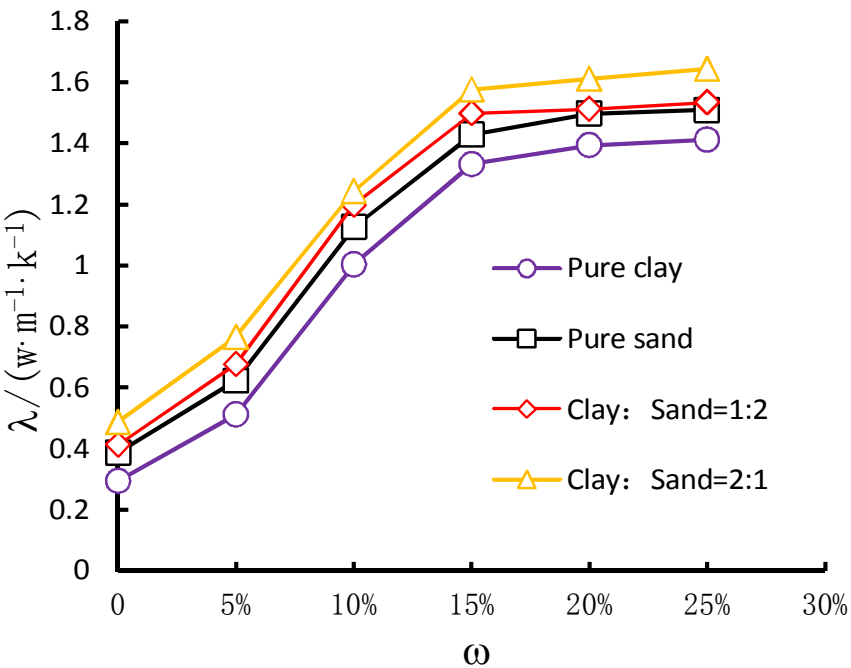

Fig.8 The curve between water content and a mixture of sand and clay

\section{The regression equation of soil sample thermal physical parameters}

To facilitate the application, we based on the formula (1) and have a further discussion about the relation among the three parameters that include the thermal conductivity of soil $(\lambda)$, water content $(\omega)$ and dry density $\left(\rho_{d}\right)$ under the above test results. Using the Matlab software, we have carried on the multiple regression analysis with the result of the experiment. We obtained the soil coefficient of thermal conductivity of fitting figure that include pure clay and sandy soils fitting figure under the different dry density and water content as well as a mixture ratio of 1:2 between sand and clay in the case of the best dry density and different water content. And according to the fitting figure, we fit a formula of the corresponding situation. 


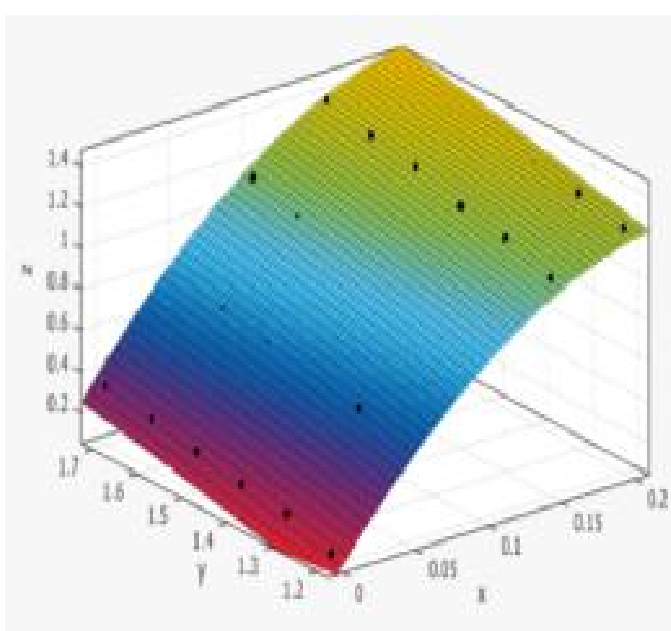

Fig.9 The pure clay fitting figure

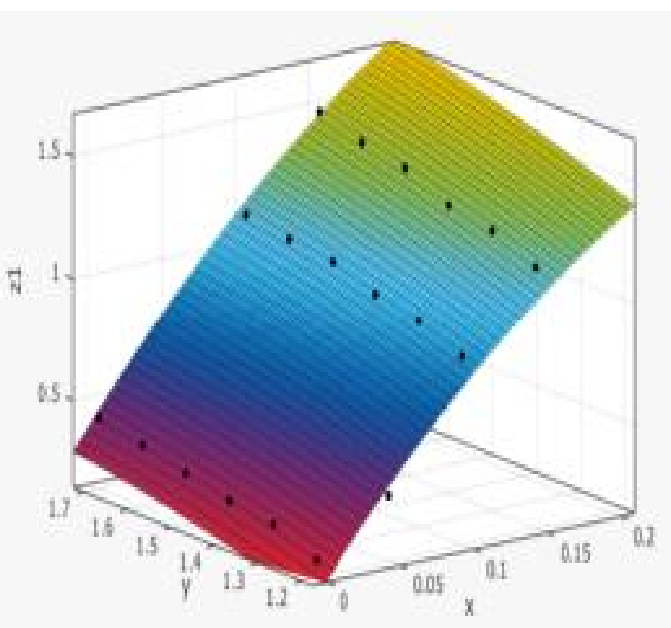

Fig.10 The pure sand fitting figure

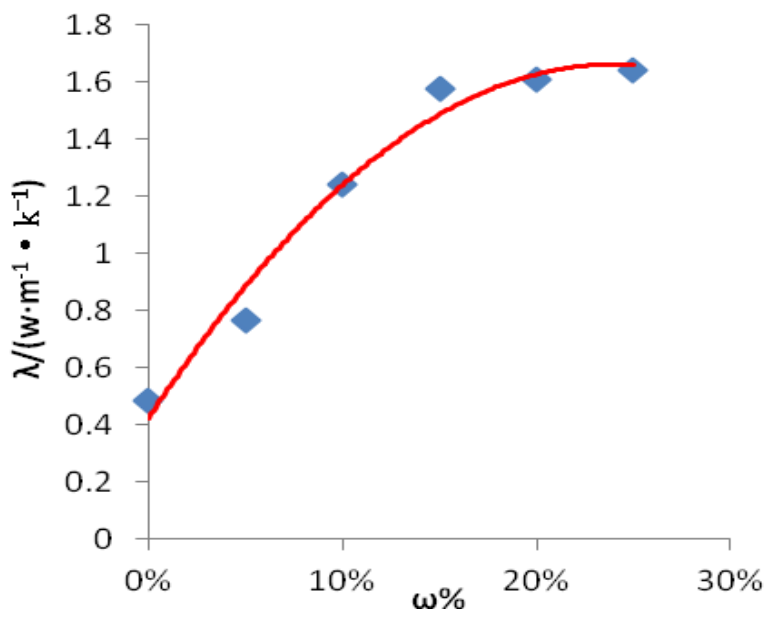

Fig.11 The ratio of sand and clay fitting figure 2:1

(1)Pure clay fitting formula is as follows (Fig.9) :

$$
\lambda=-0.73+9.771 \omega+0.8446 \rho_{d}-19.65 \omega^{2}-0.1443 \omega \rho_{d}-0.1277 \rho_{d}^{2}(7)
$$

The correlation coefficient of fitting: $\mathbb{R}^{2}=0.9949$

(2) Pure sand fitting formula is as follows (Fig.10) :

$$
\lambda=-0.8939+7.451 \omega+1.2181-10.18 \omega^{2}-0.548 \omega \rho_{d}-0.2797 \rho_{d}^{2}
$$

The correlation coefficient of fitting: $R^{2}=0.9726$

(3)The Coefficient of thermal conductivity fitting formula is as follows under different water content when the ratio of mixture between sand and clay is $2 ; 1$ and dry density is $1.6 \mathrm{~g} / \mathrm{cm} 3$.(Fig.11)

$$
\lambda=21.448 \omega^{2}+10.3 \omega+0.4252
$$

The correlation coefficient of fitting: $R^{2}=0.9779$

According to the above analysis, the correlation coefficient $\mathrm{R}^{2}$ is greater than 0.9 , and is close to 1. It shows that the effect of fitting is fine and the result is closely related to variable factors.

\section{Conclusions}

(1)According to the principle of Transient Plane Source, the soil thermal conductivity coefficient under different dry density, different water content and different soil composition were analyzed. It was founded that the method of Transient Plane source is faster than others when the soil moisture is not evaporated. It is further determined that with the increase of water content, soil coefficient of thermal conductivity is bigger and bigger when the dry density is kept constant.

Experiments show that the soil thermal conductivity increases a little when the water content ranges from $0 \%$ to $15 \%$. The soil thermal conductivity increases slowly when the water content is more than $15 \%$, but it still increases with the increase of the water content.

(2) Four types of soil samples were taken from Wuhan, including pure clay, pure sand, mixing ratio of 1: 2 between clay and sand and the mixing ratio of 2: 1 between clay and sand. The test results show that the soil thermal conductivity of clay and sand mixed with 2: 1 is higher than that of others, it can be used as buried pipes for filling according to the different soil conditions in different areas.

(3) According to the test results, the fitting formulas of thermal conductivity of three soil samples were fitted by Matlab software, which could be used to determine the thermal conductivity of the soil in practical engineering, and provide references for related projects. 


\section{Acknowledgements}

This work was financially supported by the Foundation Item(NSFC , Serial number: 51408201 and 51609081 ).

\section{References}

[1]Pingfang $\mathrm{Hu}$, Zhi Huang, Xinming Sun,etc. Development status of study and application of ground-source heat pump technology. [J] In chinese, Refrigeration \& Air-Conditioning 2014,12:104-109.

[2]Kavanaugh S. P. Field tests for ground thermal properties methods and impact on ground source heat pump design. ASHRAE Transactions, 1992, 98 (2): 607-615.

[3]LINES, CHANGPR, LUHJYS. Formulation and optimization of cubic polynomial joint trajectories for industrial robots [J].IEEE Transactions on Automatic Control, 1983, AC-28(12): 1066-1073.

[4]Hong-jun Xiao, Fan Yu, Xin-xin Zhang. Thermal conductivity measurement of materials based on a transient hot-plane method [J]. In chinese, Journal of University of Science and Technology Beijing,2012,12:1432-1436.

[5]Log T, Gustasson S E. Transient Plane Source(TPS) Technique for Measuring Thermal Transport Properties of Building Materials.Fire and Materials, 1995,19(1):43-49

[6]Hungpu Hongwang,Jin Hua. [J]. On the impact of water content on engineering common soil coefficient of thermal conductivity test research Water Resource and Power ,in chinese.2015,12:122-124. 